University of Wollongong

Research Online

Faculty of Engineering and Information

Faculty of Engineering and Information

Sciences - Papers: Part B

Sciences

2017

Physical, hydraulic, and mechanical properties of clayey soil stabilized by lightweight alkali-activated slag geopolymer

Yan Jun Du

Southeast University

Bo Wei Yu

Southeast University

Kai Liu

Southeast University

Ning Jun Jiang

University of Cambridge

Martin D. Liu

University of Wollongong, martindl@uow.edu.au

Follow this and additional works at: https://ro.uow.edu.au/eispapers1

Part of the Engineering Commons, and the Science and Technology Studies Commons

Research Online is the open access institutional repository for the University of Wollongong. For further information contact the UOW Library: research-pubs@uow.edu.au 


\title{
Physical, hydraulic, and mechanical properties of clayey soil stabilized by lightweight alkali-activated slag geopolymer
}

\begin{abstract}
Lightweight cement materials are extensively used in the infrastructure construction. Geopolymer is a low-carbon and environmentally friendly cementitious material. This paper presents an investigation on the physical, hydraulic, and mechanical characteristics of lightweight geopolymer stabilized soil (LGSS) and a comparison with lightweight cement stabilized soil (LCSS). Measurements of volumetric absorption (VA) of water, hydraulic conductivity (k), and unconfined compressive strength (qu), scanning electron microscope (SEM) observation, mercury intrusion porosimetry (MIP) test, and thermogravimetric analysis (TGA) are conducted. The results show that LGSS has higher VA than LCSS. The $k$ of LGSS is one order of magnitude higher than that of LCSS. The qu of LGSS is 2-3.5 times of that of LCSS. Microstructurally, the VA and k of LGSS are found to be positively correlated with the volume of large air pores $(>10 \mu \mathrm{m})$. Higher qu of LGSS than LCSS is attributed to more hydration products that fill up the voids of soil. It is concluded that LGSS gives better engineering performances than LCSS in terms of water absorption, permeability, and strength characteristics.

\section{Disciplines}

Engineering | Science and Technology Studies

\section{Publication Details}

Du, Y., Yu, B., Liu, K., Jiang, N. \& Liu, M. D. (2017). Physical, hydraulic, and mechanical properties of clayey soil stabilized by lightweight alkali-activated slag geopolymer. Journal of Materials in Civil Engineering, 29 (2), 04016217-1-04016217-10.
\end{abstract}


Physical, Hydraulic and Mechanical Properties of Clayey Soil Stabilized by Lightweight

\author{
Alkali-Activated Slag Geopolymer
}

Yan-Jun Du ${ }^{1}$, Bo-Wei Yu ${ }^{2}$, Kai Liu ${ }^{3}$, Ning-Jun Jiang ${ }^{4 *}$, S.M.ASCE, and

\author{
Martin D. Liu ${ }^{5}$
}

Abstract: Lightweight cement materials are extensively used in the infrastructure construction. Geopolymer is a low-carbon and environmentally-friendly cementitious material.

This paper presents an investigation on the physical, hydraulic, and mechanical characteristics of lightweight geopolymer stabilized soil (LGSS), and a comparison with lightweight cement stabilized soil (LCSS). Measurements of water absorption, hydraulic conductivity, and unconfined compressive strength (UCS), scanning electron microscope (SEM) observation, mercury intrusion porosimetry (MIP) test, and thermogravimetric analysis (TGA) are conducted. The results show that LGSS has higher volumetric absorption than LCSS. The hydraulic conductivity of LGSS is one order of magnitude higher than that of LCSS. The UCS of LGSS is 2 to 3.5 times of that of LCSS. Microstructurally, the volumetric absorption and hydraulic conductivity of LGSS are found to be positively correlated with the volume of large air pores $(>10 \mu \mathrm{m})$. Higher UCS of LGSS than LCSS is attributed to more hydration products that fill up the voids of soil. It is concluded that LGSS gives better engineering performances than LCSS in terms of water absorption, permeability, and strength characteristics.

\footnotetext{
1 Professor, Institute of Geotechnical Engineering, Southeast University, Nanjing 210096, China. Email: duyanjun@seu.edu.cn.

2 Graduate Student, Institute of Geotechnical Engineering, Southeast University, Nanjing 210096, China. Email: fish1991222@gmail.com.

${ }^{3}$ Graduate Student, Institute of Geotechnical Engineering, Southeast University, Nanjing 210096, China (Previously). Civil Engineer, Poly Real Estate Group Co. Ltd., Foshan 528200, China (Currently). Email: liuk1211@126.com.

${ }^{4}$ Graduate student, Institute of Geotechnical Engineering, Southeast University, China (Previously); PhD candidate, Department of Engineering, University of Cambridge, Trumpington Street, Cambridge CB2 1PZ, United Kingdom (Currently). (*Corresponding author). Email:jiangningjun@gmail.com; nj263@cam.ac.uk. Tel/Fax: +44-1223-766683

${ }^{5}$ Senior Lecturer, Faculty of Engineering, University of Wollongong, Wollongong NSW 2522, Australia. Email: martindl@uow.edu.au
} 
Keyword: Geo-materials; lightweight; geopolymer; water absorption; hydraulic conductivity; strength

\section{Introduction}

Ordinary Portland cement (OPC) is one of the prevailing construction materials in the world. However, OPC production is energy-intensive, as the raw materials need to be heated to a temperature higher than $1400^{\circ} \mathrm{C}$, which consumes substantial electrical and hydraulic energies. Its manufacturing process also consumes enormous non-renewable natural resources (1.5 tonne limestone and clay per tonne of $\mathrm{OPC}$ ). The production process also emits large amounts of greenhouse gases (e.g., 0.95 tonne carbon dioxide per tonne of OPC) and polluting chemicals (e.g., sulfur dioxide, carbon monoxide and nitric oxide), posing potential hazards to the air quality and societal sustainability. Therefore, less energy-intensive, environmentally-friendly and economic cementing materials are urgently been sought. Geopolymer, a synthetic alkali aluminosilicate material from the reaction between solid aluminosilicate and concentrated aqueous alkali hydroxide solution or hydroxide-silicate mixture solution, is a promising alternative (Davidovits 1991; Duxson et al. 2007). Its production process demands less fuel energy and emits less greenhouse gases (Davidovits 1991; Aguilar et al. 2010). A wide range of industrial waste materials containing silicate and/or alumina can be used as the solid aluminosilicate to manufacture geopolymers, such as fly ash (FA), ground granulated blastfurnace slag (GGBS), and metakaolin (Aguilar et al. 2010; Arul et al. 2015; Posi et al. 2013; Liu et al. 2014; Abdullah et al. 2015). Aqueous alkali hydroxide is also widely available from 
materials rich in sodium hydroxide or potassium hydroxide (Rowles et al. 2003; Xu et al. 2006).

As a cementitious binder, geopolymer has been proved to have prestigious engineering properties such as high mechanical strength, high thermal stability, and good durability performances, depending on the specified chemical compositions used and reaction processes involved (Bakharev 2005; Kong and Sanjayan 2008; Liu et al. 2014; Zhang et al. 2013).

Lightweight cement materials have attracted the attentions from the building construction industry for decades, due to their advantages in reducing the deadload of building structures, improving thermal and acoustic insulation efficiency of buildings and saving transportation and construction costs (Aguilar et al. 2010; Pimraksa et al. 2011; Zhang et al. 2014). In the construction of road embankments and bridge foundations on soft clay deposits, deep mixing method is commonly used to stabilize the soft soil. The settlement of the stabilized soil is largely determined by the self-weight of the stabilized soil. A reduction in the self-weight of the stabilized soil can substantially reduce the binder content needed to meet settlement requirement. Several approaches have been explored to produce the lightweight cement materials. One is to introduce air into the cement paste to reduce the material density (cellular aerated or foamed cement) (Horpibulsuk et al. 2012b, 2013, 2014; Neramitkornburi et al. 2015a, b); the other is to replace normal-weight materials in the cement or concrete with lightweight ones (Aguilar et al. 2010; Pimraksa et al. 2011; Posi et al. 2013; Liu et al. 2014; Arul et al. 2015). This study aims at the applicability of geopolymer as lightweight materials in cement and its use in soil stabilization.

To the knowledge of the authors, limited studies have been done with respect to the applications of geopolymer-based lightweight materials. One of the few studies is carried out by Suksiripattanapong et al. (2015) for the sludge-fly ash lightweight cellular geopolymer. 
Most of the existing research focuses on lightweight geopolymer concrete. Posi et al. (2013) examine the strength and density properties of lightweight geopolymer concrete containing aggregate from recycled lightweight block. Liu et al. (2014) investigate the thermal and mechanical properties of the oil palm shell foamed geopolymer concrete. Pimraksa et al. (2011) explore the syntheses of lightweight geopolymer from diatomaceous earth and rice husk ash. Aguilar et al. (2010) study the strength behavior of lightweight geopolymeric materials composed of metakaolin, fly ash and sodium silicate. It is noted that in lightweight geopolymer concrete, the geopolymer usually serves as cementitious agent and alternative lightweight materials are used as aggregates. Nevertheless, the utilization of lightweight geopolymer in soil stabilization is different from that in concrete-making since no coarse aggregate is involved. Instead, the lightweight geopolymer acts as cementitious agents as well as weight-reduction contributor in soil stabilization. The objective of this study is to investigate the physical, hydraulic, and mechanical properties of lightweight geopolymer stabilized soil (LGSS). The lightweight geopolymer is composed of ground granulated blast furnace slag (GGBS) as a precusor, sodium silicate $\left(\mathrm{Na}_{2} \mathrm{SiO}_{3}\right)$-calcium carbide residue (CCR) mixture as an alkali activator, and air foam. Normal lightweight cement stabilized soil (LCSS) is used as a benchmark.

\section{Materials and Testing Methods}

\section{Materials}

The clayey soil used in this study is collected from Nanjing, Jiangsu Province, China. Some basic properties of the clayey soil are summarized in Table 1. Based on the Unified Soil 
Classification System (ASTM 2011), this clayey soil is classified as low plasticity clay (CL). $\mathrm{Na}_{2} \mathrm{SiO}_{3}-\mathrm{CCR}$ mixture is selected as the alkali activator due to the following considerations: (1) CCR is a by-product from acetylene gas factories, and is considered as a low-carbon and environmentally-friendly binder in stabilizing silty and clayey soils (Horpibulski et al. 2012a: Jiang et al. 2016; Du et al. 2011, 2016); (2) CCR is found to be effective in activating aluminosilicate-rich materials such as fly ash and GGBS (Phetchuay et al. 2014); and (3) $\mathrm{Na}_{2} \mathrm{SiO}_{3}$ is able to further increase the strength of the geopolymers (Arul et al. 2015) because of the gel-like products generated from the aluminosilicate-sodium silicate reactions (Arul et al. 2015). CCR used in this study is sampled from the stock-pile of Nanjing Acetylene Gas Factory. Its specific gravity is 2.31 and $\mathrm{pH}$ is 12.57 . Commercially available reagent grade $\mathrm{Na}_{2} \mathrm{SiO}_{3} \cdot 9 \mathrm{H}_{2} \mathrm{O}$ (white powder form) composed of $50 \% \mathrm{SiO}_{2}$ and $50 \% \mathrm{Na}_{2} \mathrm{O}$ is used. GGBS is an industrial by-product produced during the refining of iron ore. It can be used as a partial replacement for OPC as a cementing agent (Yu et al. 2016) and soil stabilizing agent (Ktnuthia and Wild 2001; Yi et al. 2015) which can substantially increase soil resistance to sulfate-attack (Yu et al. 2016). The GGBS used in this study, which is purchased from Nanjing Iron \& Steel Group Corp., is in a gray powder form.

The chemical compositions of the parent soil, CCR, GGBS, and PC are shown in Table 2. The alkalinity of GGBS is defined as the ratio of the summed content of $\mathrm{CaO}, \mathrm{MgO}$, and $\mathrm{Al}_{2} \mathrm{O}_{3}$ to that of $\mathrm{SiO}_{2}$, which are measured through X-ray fluorescence spectrometer as shown in Table 2. The physical and chemical properties of GGBS are listed in Table 3. The specific surface area and average size of the GGBS are measured using the Brunauer-Emmett-Teller (BET) method via a Physisorption Analyzer ASAP2020. 


\section{Sample preparation}

To prepare the samples, predetermined weights of binder (air-dried CCR powder, $\mathrm{Na}_{2} \mathrm{SiO}_{3} \cdot 9 \mathrm{H}_{2} \mathrm{O}$ powder, and GGBS powder with a ratio of $8: 1: 1$ (dry weight basis) for LGSS, and predetermined weight of PC for LCSS), are firstly added into the air-dried parent soil that is passed through a sieve with an opening size less than $2 \mathrm{~mm}$. The soil-binder mixtures are then mixed with predetermined volume of distilled water thoroughly for $10 \mathrm{~min}$ via an electric agitator at the speed of $125 \mathrm{rpm}$ to obtain homogenous soil-binder slurry. Two water contents (1.6 $w_{\mathrm{L}}$ and $1.9 w_{\mathrm{L}}$ for LGSS and LCSS respectively, where $w_{\mathrm{L}}$ is the liquid limit of the parent soil) are adopted in this study to facilitate the thorough and homogeneous mixing of all the raw materials and to meet the designed target density of stabilized soils (i.e., 900, 1000, 1100, and $1200 \mathrm{~kg} / \mathrm{m}^{3}$ ). The air foam is pre-formed by mixing predetermined volume of distilled water and foaming agent with a ratio of 40:1 (v/v) as suggested by ASTM C796 (ASTM 2012) in a stainless $20 \mathrm{~L}$ air receiver, and then introducing compressed air into the air receiver with a controlled pressure of approximately $0.2 \mathrm{MPa}$ under the temperature of $20 \pm 2{ }^{\circ} \mathrm{C}$. The foaming agent, purchased from a chemical plant located in Weifang City of Shandong Province, is a viscous liquid with $\mathrm{pH}$ of approximately 6.5 to 7.5 . The foaming agent is a combination of surfactants which are originated from the tropical plant palm nuts and are processed through chemical rectification and neutralization. Predetermined volume of the preformed air foam is then mixed with the soil-binder slurry with predetermined weight for $7 \mathrm{~min}$ via the electric agitator at the speed of $125 \mathrm{rpm}$. The air foam blended slurry whose density reaches the target (i.e., $900 \mathrm{~kg} / \mathrm{m}^{3}, 1000 \mathrm{~kg} / \mathrm{m}^{3}, 1100 \mathrm{~kg} / \mathrm{m}^{3}$, or $1200 \mathrm{~kg} / \mathrm{m}^{3}$ ) is poured into a polyvinyl chloride mold with size of $\Phi 50 \times \mathrm{H} 100 \mathrm{~mm}$, wrapped by vinyl bags, and cured for 3 days under the temperature of $20 \pm 2{ }^{\circ} \mathrm{C}$ and relative humidity of $95 \%$ (hereinafter referred to as standard 
curing). The volume of water, air foam, and binder added to the soil specimens are recorded. Then the soil specimens are carefully extruded from the mold by hand, wrapped by vinyl bags, and subjected to the standard curing again until the total curing time (including initial 3 days) reaches 7 days, 14 days, 28 days, 56 days, and 90 days separately. The preparation of the LCSS follows the same manner as for the LGSS, except that Portland cement (PC) replaces the geopolymer. The lightweight geopolymer is composed of $27.8 \%$ to $44.8 \%$ geopolymer and $55.2 \%$ to $72.2 \%$ air foam $(\mathrm{w} / \mathrm{w})$. The normal lightweight cement is composed of $27.6 \%$ to $44.7 \% \mathrm{PC}$ and $55.3 \%$ to $72.4 \%$ air foam (w/w). Tables $\mathbf{4}$ and $\mathbf{5}$ show the proportions of each components within LGSS and LCSS, respectively. The water content, density and initial void ratio $\left(e_{0}\right)$ of stabilized soils are measured after the samples are cured under the standard condition for different periods (i.e., $7,14,28,56$, and 90 days). The water content here is defined as the ratio of the weight of the water to that of the total solids including soil and binder, and is determined by heating the soil in an oven at a constant temperature of $105^{\circ} \mathrm{C}$ for 24 hours.

\section{Testing Methods}

In this study, a series of laboratory tests including measurements of water absorption, hydraulic conductivity and unconfined compressive strength (UCS), scanning electron microscope (SEM) observation, mercury intrusion porosimetry (MIP) test, and thermogravimetric analysis (TGA) are performed accordingly. The macro-properties including water absorption, hydraulic conductivity and UCS of the LGSS and LCSS are assessed by the micro-scale analyses of microstructure, pore size distributions and hydration products obtained from SEM, MIP and TGA tests, respectively. The curing periods of the samples for each test are shown in Table 6. 

Consortium (2005) in which a flowability of $180 \mathrm{~mm}$ is requested. The water absorption test is performed based on the method presented by Nambiar and Ramamurthy (2007). Triplicate stabilized soil samples (of $50 \mathrm{~mm}$ in diameter and $100 \mathrm{~mm}$ in height) cured for 28 days are soaked in distilled water for 60 days at a constant temperature of $20^{\circ} \mathrm{C}$. The weights of the soil samples after soaking for $0,1,2,3,4,6,9,12,15,18,21,24,27,30,40,50$, and 60 days respectively are measured. The density of each of the three identical samples is then calculated based on the measured soil weight and volume and the average values are reported. The value of coefficient of variation (COV) is less than $5 \%$ indicating the repeatability of the test results. According to Nambiar and Ramamurthy (2007), water absorption in weight basis is not consideration, volumetric absorption (VA) of water by the soil sample is adopted in this study and it is calculated by the following equation (Madhkhan et al. 2008):

applicable for lightweight construction materials, since it can not reflect the effect of initial density on the amount of water absorbed onto the lightweight material. With this in andit is calculated by the following equation (Madhkhan et al. 2008):

$$
V A=\frac{m_{i}-m_{0}}{\rho_{w} V_{0}} \times 100 \%
$$

where $m_{0}$ is the weight of the stabilized soil samples prior to the absorption test $(\mathrm{kg}) ; m_{\mathrm{i}}$ is the weight of the stabilized soil samples immediately after $i$ th days of soaking $(\mathrm{kg}) ; V_{0}$ is the initial volume of stabilized soil $\left(\mathrm{m}^{3}\right)$; and $\rho_{w}$ is the density of water $\left(1000 \mathrm{~kg} / \mathrm{m}^{3}\right)$. It is evident from Eq. (1) that higher $V A$ value indicates that more water is absorbed on the testing sample with unit volume.

The constant-head hydraulic conductivity test is conducted using a flexible-wall permeameter according to ASTM D 5084 (ASTM 2010b). Before the test, the vacuum method 
is used to facilitate the soil saturation (Du et al. 2012). The hydraulic conductivity test is performed by applying confining pressure and upward seepage pressure of $120 \mathrm{kPa}$ and $60 \mathrm{kPa}$, respectively. The hydraulic gradient is controlled as 60. Preliminary tests show that this hydraulic gradient, though higher than that prescribed by ASTM D 5084 (ASTM 2010b), results in insignificant impact on the measured hydraulic conductivity.

UCS tests are conducted for the triplicate samples as per ASTM D 4219-08 (ASTM 2008). The rate of vertical load remains $1 \mathrm{~mm} / \mathrm{min}$ until the failure of samples. The average values are reported and the COV values are less than 5\% indicating the repeatability of the results.

The SEM observation is conducted by using a LEO1530VP scanning electron microscope. After curing for 28 days under the temperature of $20 \pm 2{ }^{\circ} \mathrm{C}$ and relative humidity of $95 \%, 1$ $\mathrm{cm} \times 1 \mathrm{~cm}$ cubic samples are extracted from samples for UCS test in a careful manner to eliminate disturbance. After being vacuum-dried and coated with gold, the cubic samples are then subjected to the SEM observation to obtain the microstructural images.

The MIP test is based on the non-wetting nature of mercury so that it can be pressurized to penetrate a porous medium (Diamond 1970). Jurin's equation is adopted to calculate the diameter of intruded pores based on the capillary theory, as all pores are assumed to be of cylindrical shape in MIP method (Mitchell and Soga 2005):

$$
d=-\frac{4 \tau \cos \theta}{p}
$$

where $d$ is the diameter of the pore intruded, $\tau$ is the surface tension of intruded liquid (i.e. mercury), $\theta$ is the contact angle, and $p$ is the applied pressure. In this study, MIP test is conducted using AUTOPORE 9500 mercury intrusion porosimeter (Micromeritics Co. Ltd., USA). The maximum applied pressure is $228 \mathrm{MPa}$ and the surface tension of mercury is $4.84 \times 10^{-4}$ $\mathrm{N} / \mathrm{mm}$ at $25^{\circ} \mathrm{C}$ (Mitchell and Soga 2005). The contact angle is taken as $135^{\circ}$. After curing for 
28 days under the temperature of $20 \pm 2{ }^{\circ} \mathrm{C}$ and relative humidity of $95 \%, 1 \mathrm{~cm} \times 1 \mathrm{~cm}$ cubic samples are extracted from samples for UCS test in a careful manner to eliminate disturbance. The cubic samples are then subjected to the MIP to obtain the pore size distributions. TGA is conducted by heating a test sample continuously from room temperature to $750{ }^{\circ} \mathrm{C}$ at a heating rate of $20{ }^{\circ} \mathrm{C} / \mathrm{min}$ in a nitrogen environment. This method is widely used to characterize cementitious compositions in cement, concrete and stabilized soils (Jin and AlTabbaa 2013; Jiang et al. 2016). In this study, TGA is performed using a differential scanning calorimeter DSC Q2000 (TA Instruments, USA). After designated curing period of 28 days, three identical cubic samples $(1 \mathrm{~cm} \times 1 \mathrm{~cm})$ are extracted and soaked in absolute ethyl alcohol for $96 \mathrm{hr}$ to terminate the hydration. The specimens are then dried at $30^{\circ} \mathrm{C}$ and ground through a 200-mesh sieve. Approximately $30 \pm 0.5 \mathrm{mg}$ sieved specimens are used for the TGA test. The results of TGA are presented as a curve of the mass loss versus temperature. The first derivative of the mass loss curve is recorded as a function of time, which is known as derivative thermogravimetric analysis (DTG).

\section{Test Results}

\section{Water Absorption}

Figure 1 presents the variations of soil density with soaking time. Error bars are also marked to show the credibility of the test results. It is evident that, at initial 3 days of soaking, the density of both LGSS and LCSS increases regardless of their initial target densities. Nevertheless, the magnitudes of density increase are quite different between LGSS and LCSS. The LGSS gains density increment ranging from $900 \mathrm{~kg} / \mathrm{m}^{3}$ to $1200 \mathrm{~kg} / \mathrm{m}^{3}$ while LCSS has much smaller density change ranging from $30 \mathrm{~kg} / \mathrm{m}^{3}$ to $100 \mathrm{~kg} / \mathrm{m}^{3}$. 
Figure 2 shows the variations in $V A$ with soaking time for both stabilized soils. Similarly

to the temporal variation of soil density, both stabilized soils display significant water absorption at the initial 3 days soaking. After this period, the $V A$ increases slowly and becomes stable after 30 days. Moreover, samples with lower target density reach higher $V A$ than those with higher target density. In particular, ultimate $V A$ in the cases of two LGSS samples denoted D900 (target density of $900 \mathrm{~kg} / \mathrm{m}^{3}$ ) and D1200 (target density of $1200 \mathrm{~kg} / \mathrm{m}^{3}$ ), are $13.6 \%$ and $8 \%$ respectively (see Fig. 2(a)), whereas they are only $4 \%$ and $1.3 \%$ for the LCSS samples with the same target density values (see Fig. 2(b)). Regardless of the target density, the $V A$ of LCSS is found to be smaller than that of LGSS, which is consistent with the results of soil density.

\section{Hydraulic conductivity}

Figure 3 depicts the void ratio $(e)$ and hydraulic conductivity $(k)$ on a semi-logarithmic scale. It can be seen that $k$ of the LGSS is approximately one order of magnitude higher than that of LCSS. Generally, the hydraulic conductivity of the soils increases with $e$. The $e$ - $\log k$ relationship is expressed by a linear function with coefficient of determination $\left(R^{2}\right)$ of 0.98 and 0.99 for LCSS and LGSS respectively, which is consistent with previous study on lime and cement stabilized natural clayey soils (Onitsuka et al. 2001)

\section{Unconfined compression strength $\left(q_{u}\right)$}

Figure 4((a) and (b)) presents the development of $q_{\mathrm{u}}$ for LGSS and LCSS, respectively. Fig. 4(c) shows the ratio of $q_{\mathrm{u}}$ of LGSS over that of LCSS. It is evident that $q_{\mathrm{u}}$ of LGSS is 2 to 3.5 times that of LCSS at the same target density. The $q_{\mathrm{u}}$ ratio is high at the early curing period 
and then tends to be stable after 28 days. Meanwhile, this ratio for the soil with lower target density (D900 and D1000) is higher than that with higher density (D1100 and D1200). Higher $q_{u, \mathrm{LGSS}} / q_{u, \mathrm{LCSS}}$ for the soil with lower target density means that strength of LGSS is less affected by the initial soil density than that of the LCSS. This is probably because that the LGSS has more formed cementitious materials (e.g. C-S-H) than the LCSS, which makes the LGSS less vulnerable to the strength deterioration from density reduction. This will be further discussed in the section of "MIP and TGA".

Consoli et al. (2012) and Horpibulsuk et al. (2011; 2012b) verify that the ratio of volume of void $(V)$ over the volume of binder ( $C$, cement in their studies) is the primary parameter affecting the engineering properties including strength and stiffness characteristics of lightweight cement stabilized clay. In this study, the parameter $V / C$ (where $V$ includes volume of water and airfoam) is adopted to evaluate the $q_{\mathrm{u}}$ of the soils and the $V / C-q_{\mathrm{u}}$ corrections are expressed by the following equation:

$$
\frac{q_{\mathrm{u}}}{p_{\mathrm{a}}}=\frac{A}{(V / C)^{B}}
$$

where $p_{\mathrm{a}}$ is the standard atmospheric pressure (100 kPa); $A$ and $B$ are dimensionless constants. The values of $A$ usually vary in relatively wide range, depending on the soil type, curing time, and air content. The values of $B$ are usually in a narrow range from 1.26 to 1.29 for cemented non- to low-swelling clays (Horpibulsuk et al. 2011). In this study, the $B$ value is set to be 1.27 for LGSS and LCSS, which is consistent with that adopted by Horpibulsuk et al. (2012b) for the lightweight cemented clays.

Figure 5((a) and (b)) shows the fitted equations where the values of parameter $A$ are determined using the Least-Square-Root fitting method. It is found that $R^{2}$ values of the fitted 
(Consoli et al. 2012; Horpibulsuk et al. 2011, 2012b). The variations of parameter $A$ with curing

time for LGSS and LCSS are shown in Fig. 5(c). The magnitudes of parameter $A$ reported in

Bangkok clay. The values of parameter $A$ for the LGSS (132 to 177) are approximately 2 to 2.4 the relationship between the parameter $A$ and curing time, which could be a useful tool for predicting $q_{\mathrm{u}}$ development of LGSS in practice.

\section{SEM, MIP and TGA}

Figure 6 shows the microstructure of LGSS and LCSS curing for 28 days. The entire bold

black line in the lower right corner represents $20 \mu \mathrm{m}$ in the image. In the case of LGSS (Fig.

6(a)), it can be found that almost the entire surface of soil aggregates are coated with reticulate hydrate products, which represents C-S-H as reported by Du et al. (2014) and Bensted and

Barnes (2002). In the case of LCSS (Fig. 6(b)), both reticulate and needle-shaped hydrate products can be observed, which are C-S-H and ettringite, respectively (Du et al. 2014; Bensted and Barnes 2002). However, these hydrate products are not found to coat the entire surface of soil aggregates. This indicates that better bonds are produced in LGSS than in LCSS. 
$(0.818 \mathrm{ml} / \mathrm{g})$. According to Horpibulsuk et al. (2009), pores in the stabilized soil can be classified as intra-aggregate pores $(d<0.01 \mu \mathrm{m})$, small inter-aggregate pores $(0.01 \mu \mathrm{m} \leq d<0.1$ $\mu \mathrm{m})$, large inter-aggregate pores $(0.1 \mu \mathrm{m} \leq d<10 \mu \mathrm{m})$ and air voids $(d>10 \mu \mathrm{m})$. Fig. 7 (b) presents the pore volume percentage of different types of pores in the soils. It is found that the volume percentage of small inter-aggregate pores and entrain air voids in the LGSS are higher than those of LCSS. The higher volume percentage of entrain air voids in the LGSS coincides with its $V A$ and $k$ shown in Figs. 2 and 3, respectively.

Figure 8 shows the TGA and DTG results for the LGSS and LCSS with $1000 \mathrm{~kg} / \mathrm{m}^{3}$ target density at $28 \mathrm{~d}$ standard curing. Only one target density is selected for TGA/DTG analysis because the purpose here is just to compare the LGSS and LCSS with the same target density. The results of TGA are presented as curves of the mass loss/derivative of mass loss versus temperature. The first derivative of the mass loss curve is recorded as a function of time, which is known as derivative thermogravimetric analysis (DTG). The peaks in DTG curves correspond to the presence of of C-S-H (main weight loss between $50{ }^{\circ} \mathrm{C}$ and $200{ }^{\circ} \mathrm{C}$ ) and $\mathrm{Ca}(\mathrm{OH})_{2}$ (main weight loss between $440{ }^{\circ} \mathrm{C}$ and $520{ }^{\circ} \mathrm{C}$ ) (Haha et al. 2011; Pane and Hansen 2005). Table 7 shows the content of C-S-H and $\mathrm{Ca}(\mathrm{OH})_{2}$ in the soils tested. The content of $\mathrm{Ca}(\mathrm{OH})_{2}$ is derived from its stoichiometric relationship with hydroscopic water loss between $440{ }^{\circ} \mathrm{C}$ and $520^{\circ} \mathrm{C}$ (Jiang et al. 2016). As C-S-H is mostly amorphous, its content could not be calculated by the stoichiometric relation. In this study, the loss of hydroscopic water corresponding to the temperature of $50^{\circ} \mathrm{C}$ to $200{ }^{\circ} \mathrm{C}$ is used to represent the content of $\mathrm{C}-\mathrm{S}-\mathrm{H}$, which is also adopted by Jiang et al. (2016). As seen in Table 7, the content of C-S-H in the LGSS $(12.68 \%)$ is higher than that in the LCSS $(6.8 \%)$, which coincides with the superior strength characteristics shown in Fig. 4. Meanwhile, the content of $\mathrm{Ca}(\mathrm{OH})_{2}$ in the LGSS and 
LCSS are $0.99 \%$ and $2.2 \%$ respectively. The higher content of C-S-H found in the LGSS indicates a higher degree of pozzolanic reaction, which leads to the consumption of $\mathrm{Ca}(\mathrm{OH})_{2}$.

\section{Discussion}

The water adsorption tests show that LGSS has higher VA than LCSS (see Fig. 2). In addition, the hydraulic conductivity tests show that LGSS display higher $k$ value than LCSS at a given void ratio (see Fig. 3). It is also found that the $V A$ and $k$ values of LGSS are positively correlated with the volume of large air pores $(>10 \mu \mathrm{m})$ as shown in Fig. 9. This is fundamentally due to the fact that the $V A$ and $k$ depend on the volume of interconnected large pores (Mitchell and Soga 2005; Wang et al. 2005; Horpibulsuk et al. 2009). Since the pores with diameter $>10 \mu \mathrm{m}$ are mostly air pores (Horpibulsuk et al. 2009) and are readily available for water intrusion, then it can be expected that $V A$ and $k$ of LGSS are higher than those of LCSS since LGSS has larger volumes of air pores. In addition, alkali-activated geopolymer can form several micro-pores after the geopolymerization process, making the geopolymer more porous than PC (Rovnaník 2010; Nimwinya et al. 2016). This can also substantiate the higher values of water absorption and hydraulic conductivity of LGSS than LCSS.

In contrast, the UCS tests show that $q_{\mathrm{u}}$ of LGSS is higher than that of LCSS regardless of the target density (see Fig. 4). A possible reason is attributed to the larger amount of C-S-H formed in the LGSS $(12.68 \%)$ than LCSS $(6.8 \%)$, which is substantiated from the TGA results, shown in Table 7. The larger amount of C-S-H formed in stabilized soil would result in greater bonding strength between soil particles and higher $q_{\mathrm{u}}$ of the soil as a consequence (Chew et al. 2004; Du et al. 2014; Jiang et al. 2016; Shen et al. 2016). 


\section{Practice Implications}

The results presented in this study demonstrate that LGSS exhibits higher volumetric water absorption than LCSS. This implies that LGSS has a higher tendency to absorb and transmit water. Therefore, the penetration of deleterious materials like sulfate and chloride into LGSS may be easier than LCSS. However, Liu et al. (2015) indicate that LGSS possesses much higher sulfate resistance than LCSS in terms of higher $q_{\mathrm{u}}$ and density after soaking in concentrated sulfate sodium solution, indicating that LGSS has superior durability when exposed to sulfate-rich environmental conditions like coastal areas and sulfate-rich soils. The measured higher $k$ of LGSS indicates that LGSS is more suitable to be used in scenarios where permeability needs to be retained. In addition, the higher $q_{\mathrm{u}}$ of LGSS implies that LGSS may provide higher bearing capacity for soil infrastructures in practice.

\section{Conclusions}

A comprehensive investigation of the physical, hydraulic, and mechanical characteristics of lightweight geopolymer stabilized soil (LGSS) and a comparative study with that of lightweight cement stabilized soil (LCSS) are made in this paper. Generally speaking LGSS is a better option for soil improvement in geotechnical engineering. Microstructurally, LGSS soil aggregate is fully coated by hydrate products while LCSS is not. The volume percentage of small inter-aggregate pores and entrain air voids in the LGSS are higher than those of LCSS. Consequently LGSS has more large air pores $(>10 \mu \mathrm{m})$ than LCSS. This leads to more water absorbility, higher permeability, and greater material strength than LCSS, which are key parameters for the performance of soil improvement. Following characteristics of the improved soil are observed in this study: 
(1) LGSS exhibits higher $V A(\sim 7 \%$ to $14 \%)$ than LCSS ( $1.3 \%$ to $4 \%)$. The $k$ of LGSS is 10 times higher than that of LCSS. The $k$ values of both LGSS and LCSS on logarithmic scale are found to increase linearly with void ratio.

(2) The $q_{\mathrm{u}}$ of LGSS is 2 to 3.5 times that of LCSS at the same density and curing time. $q_{\mathrm{u}}$ is correlated with $V / C$ in a power function.

(3) The content of C-S-H in the LGSS (12.68\%) is higher than that in the LCSS (6.8\%).

(4) The $V A$ and $k$ values of LGSS are found to be positively correlated with the volume of large air pores $(>10 \mu \mathrm{m})$, which is because of the dependence of $V A$ and $k$ on the volume of interconnected large pores. The $q_{\mathrm{u}}$ of LGSS is found to be higher than that of LCSS, attributed to more hydration products that fill up the voids of soil, which is substantiated by the fact that more C-S-H is found in the LGSS than in the LCSS from the TGA test.

\section{Acknowledgements}

This research is financially supported by the National Natural Science Foundation of China (Grant No. 51278100, 41330641, and 41472258) and the Natural Science Foundation of Jiangsu Province (Grant No. BK2012022).

\section{References}

Abdullah, M., Tahir, M., Hussin, K., Zuber, S., Abdullah, M., Ghazali, R., Ahmad, F., and Binhussain, M. (2015). “Geopolymerization method for soil stabilization application.” United States Patent Application Publication, Pub. No.: US 2015/0016895 A1.

Aguilar, R. A., Diaz, B., and Garcia, J. I. E. (2010). "Lightweight concretes of activated 
metakaolin-fly ash binders, with blast furnace slag aggregates." Constr. Build. Mater., (24)7, 1166-1175.

Arul A., Kua T., Phetchuay, C., Horpibulsuk, S., Mahghoolpilehrood, F., and Disfani, M. (2015). "Spent coffee grounds-fly ash geopolymer used as an embankment structural fill material.

" J. Mater. Civil Eng., doi: 10.1061/(ASCE)MT.1943-5533.0001496

ASTM. (2008). "Standard test method for unconfined compressive strength index of chemicalgrouted soils." ASTM D 4219-08, West Conshohocken, PA.

ASTM. (2010a). "Standard test methods for liquid limit, plastic limit, and plasticity index of soils." ASTM D4318-10, West Conshohocken, PA.

ASTM. (2010b). "Standard test methods for measurement of hydraulic conductivity of saturated porous materials using a flexible wall permeameter." ASTM D5084-10, West Conshohocken, PA.

ASTM. (2011). "Standard practice for classification of soils for engineering purposes (Unified Soil Classification System)." ASTM D2487-11, West Conshohocken, PA.

ASTM. (2012). "Standard test method for foaming agents for use in producing cellular concrete using preformed foam." ASTM C796/C796M, West Conshohocken, PA.

ASTM. (2013). "Standard test method for pH of soils." ASTM D4972-13, West Conshohocken, PA.

Bakharev, T. (2005). "Resistance of geopolymer materials to acid attack." Cem. Concr. Res., $35(4), 658-70$.

Bensted, J., and Barnes, P. (2002). "Structure and Performance of Cements.” Spon Press, New York.

Chew, S. H., Kamruzzaman, A. H. M., and Lee, F. H. (2004). "Physicochemical and engineering 
Consoli, N. C., Cruz, R. C., da Fonseca, A. V., and Coop, M. R. (2012). "Influence of cementvoids ratio on stress-dilatancy behavior of artificially cemented sand." J. Geotech. Geoenviron. Eng., (138)1, 100-109.

Davidovits, J. (1991). “Geopolymers.” J. Therm. Anal., 37(8), 1633-1656.

Diamond, S. (1970). "Pore size distributions in clays." Clays Clay Miner., 18 (1), 7-23.

Du, Y. J., Zhang, Y. Y., and Liu, S. Y. (2011). "Investigation of strength and California bearing ratio properties of natural soils treated by calcium carbide residues." Proc., Geo-Frontiers, ASCE, Reston, VA, 1237-1244.

Du, Y. J., Jiang, N.J., Shen, S. L., and Jin, F. (2012). "Experimental investigation of influence of acid rain on leaching and hydraulic characteristics of cement-based solidified/stabilized lead contaminated clay.” J. Hazard. Mater., 225-226, 195-201.

Du, Y.J., Jiang, N.J., Liu, S.Y., Jin, F., Singh, D.N., and Puppala, A.J. (2014). “Engineering properties and microstructural characteristics of cement-stabilized zinc-contaminated kaolin.” Can. Geotech. J., 51(3), 289-302.

Du, Y. J., Jiang, N. J., Liu, S.Y., Horpibulsuk, S., and Arulrajah, A. (2016). "Field evaluation of soft highway subgrade soil stabilized with calcium carbide residue." Soils Found., 56(2), 301-314.

Duxson, P., Fernandez-Jimenez, A., Provis, J. L., Lukey, G. C., Palomo, A., and van Deventer, J. S. J. (2007). “Geopolymer technology: the current state of the art.” J. Mater. Sci., 42(9), 2917-2933.

Haha, M. B., Lothenbach, B., and Saout, L. G. (2011). "Influence of slag chemistry on the hydration of alkali-activated blast-furnace slag-Part I: Effect of MgO." Cem. Concr. Res., 
41(9), 955-963.

428

HGS Research Consortium. (2005). High grade soil (HGS)-foam mixed stabilized soil method. Public Work Research Institute, Japan.

Horpibulsuk, S., Rachan, R., and Raksachon, Y. (2009). "Role of fly ash on strength and microstructure development in blended cement stabilized silty clay." Soils Found., 49(1), 85-98.

Horpibulsuk, S, Rachan, R., Suddeepong, A., and Chinkulkijniwat, A. (2011). "Strength development in cement admixed Bangkok clay: laboratory and field investigations.” Soils Found. 51(2): 239-251.

Horpibulsuk, S, Phetchuay, C, and Chinkulkijniwat, C. (2012a). "Soil stabilization by calcium carbide residue." J. Mater. Civ. Eng., 24(2):184-193.

Horpibulsuk, S., Suddeepong, A., Chinkulkijniwat, A., Liu, M. D. (2012b). "Strength and compressibility of lightweight cemented clays." Appl. Clay Sci., 69, 11-21.

Horpibulsuk, S., Rachan, R., Suddeepong, A., Liu, M.D., and Du, Y.J. (2013). "Compressibility of lightweight cemented clays." Eng. Geol., 159: 59-66.

Horpibulsuk, S., Suddeepong, A., Suksiripattanapong, C., Chinkulkijniwat, A., Arulrajah, A., and Disfani, M. (2014). "Water-void to cement ratio identity of lightweight cellularcemented material." J. Mater. Civ. Eng., 26(10), 06014021.

Jiang, N. J., Du, Y. J., Liu, S. Y., Wei, M. L., Horpibulsuk, S., and Arulrajah, A. (2016). "Multiscale laboratory evaluation of the physical, mechanical and microstructural properties of soft highway subgrade soil stabilized with calcium carbide residue." Can. Geotech. J., 53(3), 373-383.

Jin, F. and Al-Tabbaa, A. (2013). "Thermogravimetric study on the hydration of reactive 
Kong, D. L. Y., and Sanjayan, J. G. (2008). "Damage behavior of geopolymer composites exposed to elevated temperatures." Cem. Concr. Compos., 30, 986-991.

Ktnuthia, J.M., and Wild, S., (2001). "Effects of some metal sulfates on the strength and swelling properties of lime-stabilised kaolinite.” Int. J. Pav. Eng., 2(2), 103-120.

Liu, M.Y.J., Alengaram, U.J., Jumaat, M.Z., and Mo, K.H. (2014). "Evaluation of thermal conductivity, mechanical and transport properties of lightweight aggregate foamed geopolymer concrete." Energy Build., 72, 238-245.

Madhkhan, M., Hosseinpoor, M., Nezhad, E. F., Talebian, A., Mirfendereski, G. A., Esmaeelkhanian, B., and Sichani, M. E. (2008). "Effect of silica fume on water absorption of structural lightweight concrete containing saturated leca fine aggregates." Proc., 33rd Conference on Our World in Concrete \& Structures, CI-Premier PTE LTD, Singapore, 100033026.

Mitchell, J.K., and Soga, K. (2005). Fundamentals of soil behavior, John Wiley \& Sons, Hoboken, USA.

Nambiar, E. K. K., and Ramamurthy, K.(2007). "Sorption characteristics of foam concrete." Cem. Concr. Res., 37(9), 1341-1347.

Neramitkornburi, A., Horpibulsuk, S., Shen, S.L., Arulrajah, A., and Disfani, M.M. (2015a). "Engineering properties of lightweight cellular cemented clay-fly ash material." Soils Found., 55(2), 471-483.

Neramitkornburi, A., Horpibulsuk, S., Shen, S.L., Chinkulkijniwat, A., Arulrajah, A., and Disfani, M.M. (2015b). "Durability against wetting-drying cycles of sustainable Lightweight Cellular Cemented construction material comprising clay and fly ash wastes." 
Nimwinya, M., Arjharn, W., Horpibulsuk, S., Phoo-ngernkham, T., and Poowancum, A. (2016). “A sustainable calcined water treatment sludge and rice husk ash geopolymer." J. Clean. Prod., 119, 128-134.

Onitsuka, K., Modmoltin, C., and Kouno, M. (2001). "Investigation on microstructure and strength of lime and cement stabilized Ariake clay." Rep. Fac. Sci. Engrg. Saga Univ., 30(1), 49-63.

Pane, I., and Hansen, W. (2005). "Investigation of blended cement hydration by isothermal calorimetry and thermal analysis." Cem. Concr. Res., 35(6), 1155-1164.

Phetchuay, C., Horpibulsuk, S., Suksiripattanapong, C., Chinkulkijniwat, A., Arulrajah, A., and Disfani M. M. (2014). "Calcium carbide residue: alkaline activator for clay-fly ash geopolymer." Constr. Build. Mater., 69, 285-294.

Pimraksa, K., Chindaprasirt, P., Rungchet, A., Sagoe-Crentsil, K., and Sato, T. (2011). "Lightweight geopolymer made of highly porous siliceous materials with various $\mathrm{Na}_{2} \mathrm{O} / \mathrm{Al}_{2} \mathrm{O}_{3}$ and $\mathrm{SiO}_{2} / \mathrm{Al}_{2} \mathrm{O}_{3}$ ratios." Mater. Sci. Eng., 528, 6616-6623.

Posi, P., Teerachanwit, C., Tanutong, C., Limkamoltip, S., Lertnimoolchai, S, Sata, V., and Chindaprasirt, P. (2013). "Lightweight geopolymer concrete containing aggregate from recycle lightweight block." Mater. Design, 52, 580-586.

Rovnaník, P. (2010). "Effect of curing temperature on the development of hard structure of metakaolin-based geopolymer.” Constr. Build. Mater., 24(7), 1176-1183.

Rowles, M., and O'Connor, B. (2003). "Chemical optimisation of the compressive strength of aluminosilicate geopolymers synthesised by sodium silicate activation of metakaolinite." $\boldsymbol{J}$. Mater. Chem., 13(5), 1161-1165. 
Shen, S.L., Cui, Q. L., Ho, C. E., and Xu, Y.S. (2016). “Ground response to multiple parallel microtunneling operations in cemented silty clay and sand." J. Geotech. Geoenviron. Eng., 142(5), 04016001.

Suksiripattanapong, C., Horpibulsuk, S., Boongrasan, S., Udomchai, A., Chinkulkijniwat, A., and Arulrajah, A. (2015). "Unit weight, strength and microstructure of a water treatment sludge-fly ash lightweight cellular geopolymer.” Constr. Build. Mater., 94, 807-816.

Wang, K. S., Chiou, J., Chen, C. H., and Wang, D. (2005). "Lightweight properties and pore structure of foamed material made from sewage sludge ash." Constr. Build. Mater., 19(8), 627-633.

Xu, J. Z., Zhou, Y. L., Chang, Q., and Qu, H. Q. (2006). "Study on the factors of affecting the immobilization of heavy metals in fly ash-based geopolymers." Mater. Lett., 60, 820-822.

Yi, Y., Gu, L., and Liu, S. (2015). "Microstructural and mechanical properties of marine soft clay stabilized by lime-activated ground granulated blastfurnace slag." Appl. Clay Sci., 103, 71-76.

Yu, B., Du, Y., Jin, F., and Liu, C. (2016). "Multi-scale study of sodium sulfate-soaking durability of low plastic clay stabilized by reactive magnesia-activated ground granulated blast-furnace slag.” J. Mater. Civ. Eng., 28(6), 04016016.

Zhang, M., Guo, H., El-Korchi, T., Zhang, Guo., and Tao, M. (2013). “Experimental feasibility study of geopolymer as the next-generation soil stabilizer." Constr. Build. Mater., 47, 14681478.

Zhang, Z., Provis, J.L., Reid, A., and Wang, H. (2014). "Geopolymer foam concrete: An emerging material for sustainable construction." Constr. Build. Mater., 56, 113-127. 
519 Table 1. Properties of clayey soil used in this study

\begin{tabular}{|c|c|}
\hline Index & Value \\
\hline $\mathrm{pH}^{\mathrm{a}}$ & 7.94 \\
\hline Specific gravity, $G_{\mathrm{s}}$ & 2.69 \\
\hline Plastic limit, $w_{\mathrm{p}}(\%)^{\mathrm{b}}$ & 22.68 \\
\hline Liquid limit, $w_{\mathrm{L}}(\%)^{\mathrm{b}}$ & 43.21 \\
\hline \multicolumn{2}{|l|}{ Grain size distribution $(\%)^{c}$} \\
\hline Clay $(<0.002 \mathrm{~mm})$ & 7.91 \\
\hline Silt $(0.002-0.02 \mathrm{~mm})$ & 30.49 \\
\hline Sand $(0.02-2 \mathrm{~mm})$ & 61.6 \\
\hline
\end{tabular}

${ }^{a}$ Based on ASTM D4972 (ASTM, 2013).

$521{ }^{\mathrm{b}}$ Based on ASTM D4318 (ASTM, 2010a).

522

${ }^{\mathrm{c}}$ Measured using a laser particle size analyzer Mastersizer 2000. 
526 Table 2. The chemical compositions of the parent clayey soil, OPC, GGBS, and CCR

\begin{tabular}{lllll}
\hline \multirow{2}{*}{ Oxide composition } & \multicolumn{4}{c}{ Content by mass (\%) } \\
\cline { 2 - 5 } & Parent soil & PC & GGBS & CCR \\
\hline $\mathrm{CaO}$ & 5.31 & 63.72 & 34.0 & 67.2 \\
$\mathrm{SiO}_{2}$ & 61.53 & 20.15 & 34.3 & 3.94 \\
$\mathrm{Al}_{2} \mathrm{O}_{3}$ & 14.19 & 4.39 & 17.9 & 0.28 \\
$\mathrm{SO}_{3}$ & - & 3.21 & 1.64 & 0.42 \\
$\mathrm{MgO}$ & 1.86 & 0.78 & 6.02 & 0.048 \\
$\mathrm{Fe}_{2} \mathrm{O}_{3}$ & 4.54 & 2.89 & 1.02 & 0.15 \\
$\mathrm{~K}_{2} \mathrm{O}$ & 2.42 & 0.90 & 0.64 & - \\
$\mathrm{TiO}_{2}$ & 0.81 & 0.22 & 1.17 & 0.071 \\
$\mathrm{Na}_{2} \mathrm{O}$ & 0.13 & - & 0.25 & - \\
\hline
\end{tabular}

527

528

529 
530 Table 3. Basic physical and chemical properties of GGBS

\begin{tabular}{lll}
\hline Material & Property & Value \\
\hline GGBS & Alkalinity a & 1.689 \\
& Specific surface area $\left(\mathrm{m}^{2} / \mathrm{g}\right)$ & 0.2932 \\
& Average grain size $(\mathrm{nm})$ & 98.525 \\
& pH (liquid to solid ratio $=1: 1)^{\mathrm{b}}$ & 10.96 \\
\hline
\end{tabular}

${ }^{a}$ The alkalinity of the GGBS is defined as the ratio of contents of $\mathrm{CaO}, \mathrm{MgO}$, and $\mathrm{Al}_{2} \mathrm{O}_{3}$ to that of $\mathrm{SiO}_{2}$

532

${ }^{\mathrm{b}}$ Based on ASTM D4972 (ASTM, 2013)

533

534 
Table 4. The proportions of each component within lightweight geopolymer stabilized soil

\begin{tabular}{ccccccccc}
\hline \multirow{2}{*}{ Designation } & $\begin{array}{l}\text { Water } \\
\left(\mathrm{kg} / \mathrm{m}^{3}\right)\end{array}$ & $\begin{array}{l}\mathrm{Na}_{2} \mathrm{SiO}_{3} \\
.9 \mathrm{H}_{2} \mathrm{O} \\
\left(\mathrm{kg} / \mathrm{m}^{3}\right)\end{array}$ & $\begin{array}{l}\mathrm{CCR} \\
\left(\mathrm{kg} / \mathrm{m}^{3}\right)\end{array}$ & $\begin{array}{l}\mathrm{GGBS} \\
\left(\mathrm{kg} / \mathrm{m}^{3}\right)\end{array}$ & $\begin{array}{l}\text { Soil } \\
\left(\mathrm{kg} / \mathrm{m}^{3}\right)\end{array}$ & $\begin{array}{l}\text { Foam } \\
\left(\mathrm{kg} / \mathrm{m}^{3}\right)\end{array}$ & $\begin{array}{l}\text { Target } \\
\text { density } \\
\left(\mathrm{kg} / \mathrm{m}^{3}\right)\end{array}$ & $\begin{array}{l}\text { Measured } \\
\text { density } \\
\left(\mathrm{kg} / \mathrm{m}^{3}\right)\end{array}$ \\
\hline $\mathrm{D} 900$ & 278 & 19.25 & 19.25 & 154 & 385 & 500 & 900 & 906.69 \\
$\mathrm{D} 1000$ & 307 & 21.5 & 21.5 & 172 & 430 & 440 & 1000 & 1028.05 \\
D1100 & 339 & 23.75 & 23.75 & 190 & 475 & 380 & 1100 & 1095.40 \\
D1200 & 370 & 26 & 26 & 208 & 520 & 320 & 1200 & 1199.65 \\
\hline
\end{tabular}

536

537 
Table 5. The proportions of each component within normal lightweight cement stabilized soil

\begin{tabular}{ccccccc}
\hline Designation & $\begin{array}{c}\text { Water } \\
\left(\mathrm{kg} / \mathrm{m}^{3}\right)\end{array}$ & $\begin{array}{c}\text { Cement } \\
\left(\mathrm{kg} / \mathrm{m}^{3}\right)\end{array}$ & $\begin{array}{c}\text { Soil } \\
\left(\mathrm{kg} / \mathrm{m}^{3}\right)\end{array}$ & $\begin{array}{c}\text { Air foam } \\
\left(\mathrm{kg} / \mathrm{m}^{3}\right)\end{array}$ & Target density $\left(\mathrm{kg} / \mathrm{m}^{3}\right)$ & $\begin{array}{c}\text { Measured } \\
\text { density } \\
\left(\mathrm{kg} / \mathrm{m}^{3}\right)\end{array}$ \\
\hline D900 & 318 & 187 & 375 & 490 & 900 & 900.12 \\
D1000 & 356 & 210 & 420 & 428 & 1000 & 991.08 \\
D1100 & 390 & 230 & 460 & 373 & 1100 & 1079.15 \\
D1200 & 428 & 252 & 505 & 312 & 1200 & 1186.35 \\
\hline
\end{tabular}

539

540

541 
542 Table 6. Summary of various testing conditions

\begin{tabular}{ccc}
\hline Test & Target density $\left(\mathrm{kg} / \mathrm{m}^{3}\right)$ & Curing time (day) \\
\hline Water absorption & $900,1000,1100,1200$ & 28 \\
Hydraulic conductivity & $900,1000,1100,1200$ & 28 \\
UCS & $900,1000,1100,1200$ & $7,14,28,56,90$ \\
SEM $^{\mathrm{b}}$, MIP $^{\mathrm{c}}$, TGA $^{\mathrm{d}}$ & 1000 & 28 \\
\hline
\end{tabular}

${ }^{a}$ Unconfined compressive strength

$544 \quad{ }^{\mathrm{b}}$ Scanning electron microscope

$545{ }^{\mathrm{c}}$ Mercury intrusion porosimetry

$546 \quad{ }^{\mathrm{d}}$ Thermogravimetric analysis

547

548

549

550 
551

Table 7. The proportion of hydration products in the lightweight stabilized soil

\begin{tabular}{llcc}
\hline Hydration & Temperature of water loss $\left({ }^{\circ} \mathrm{C}\right)$ & \multicolumn{2}{c}{ Proportion of weight $(\%)$} \\
\cline { 3 - 4 } products & & LCSS & LGSS \\
\hline $\mathrm{C}-\mathrm{S}-\mathrm{H}$ & $50-200$ & 6.8 & 12.68 \\
$\mathrm{Ca}(\mathrm{OH})_{2}$ & $440-520$ & 2.2 & 0.99 \\
\hline
\end{tabular}

552

553 
554 Table 8. Correlations between volumetric absorption (VA), hydraulic conductivity $(k)$ and

555 percentage of pores with size larger than $10 \mu \mathrm{m}$

\begin{tabular}{ccc}
\hline $\begin{array}{c}\text { Volumetric water absorption } \\
(\%)\end{array}$ & $\begin{array}{c}\text { Hydraulic conductivity } \\
(\mathrm{m} / \mathrm{s})\end{array}$ & $\begin{array}{c}\text { Percentage of pores with size } \\
\text { larger than } 10 \mu \mathrm{m}(\%)\end{array}$ \\
\hline 12.2 & $2.06 \times 10^{-7}$ & 43.1 \\
3.4 & $2.32 \times 10^{-8}$ & 34.7 \\
\hline
\end{tabular}

556

557 


\section{List of Figure Captions}

559 Fig. 1. Variations of soil density with soaking time: (a) LGSS and (b) LCSS

560 Fig. 2. Variations of water absorption with soaking time: (a) LGSS and (b) LCSS

561 Fig. 3. Variations of hydraulic conductivity $(k)$ with void ratio $(e)$

562 Fig. 4. Variations of $q_{\mathrm{u}}(\mathrm{SD}<5 \%)$ for lightweight stabilized soil with the curing time: (a) LGSS;

(b) LCSS; and (c) $q_{\mathrm{u}, \mathrm{LGSS}} / q_{\mathrm{u}, \mathrm{LCSS}}$

Fig. 5. Relationship between $q_{u} / p_{\mathrm{a}}$ and $V / C$ for lightweight stabilized soil: (a) LGSS; (b) LCSS;

565 and (c) variations of parameter $A$ obtained from Eq. (3) with curing time.

566 Fig. 6. SEM images of samples curing for 28 days: (a) LGSS; (b) LCSS

567 Fig. 7. Pore size distributions of LGSS and LCSS curing for 28 days: (a) cumulative pore

568 volume and (b) pore volume percentage

569 Fig. 8. TGA/DTA data of LGSS and LCSS curing for 28 days: (a) LGSS and (b) LCSS 

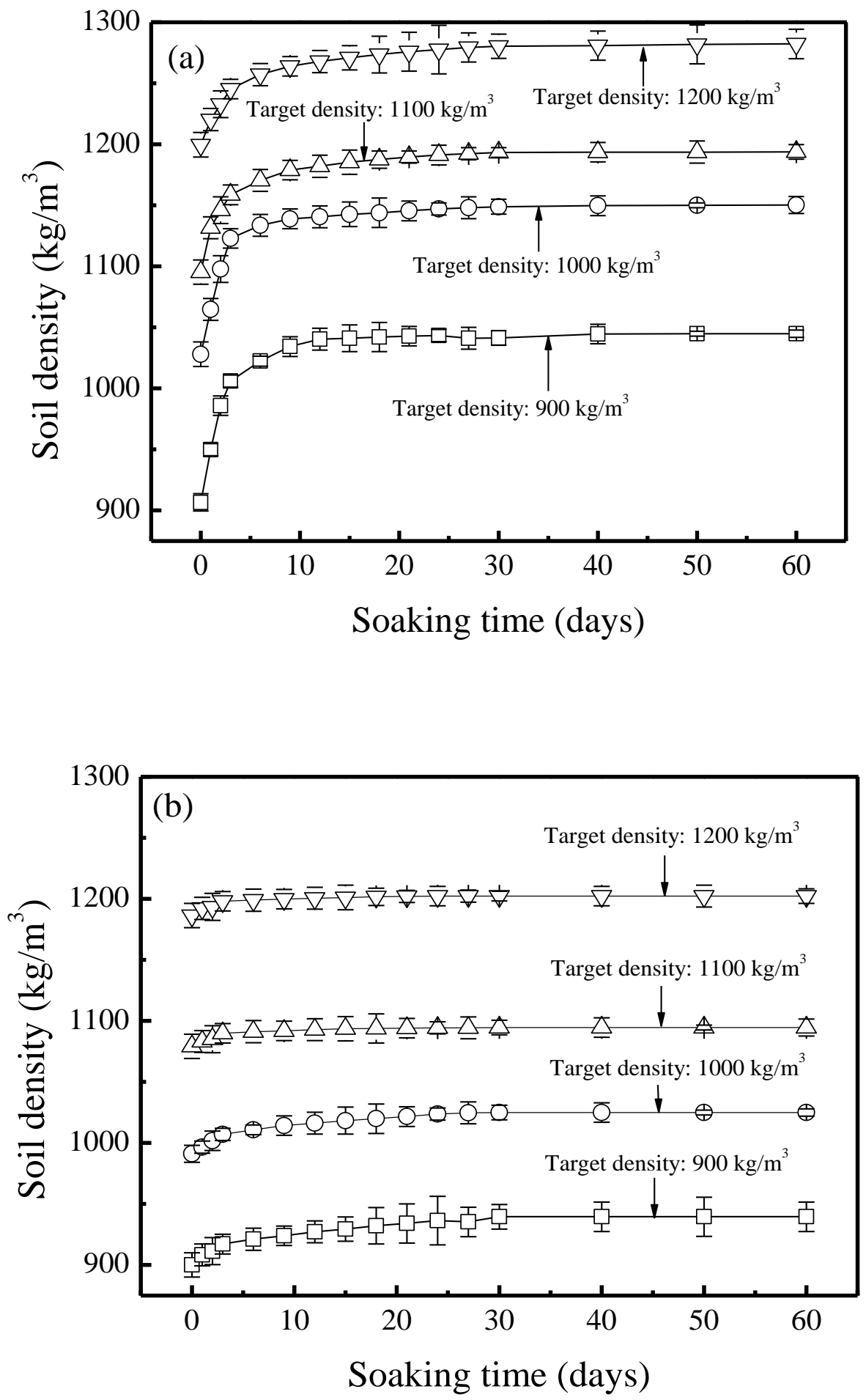

Fig. 1. Variations of soil density with soaking time: (a) LGSS and (b) LCSS 

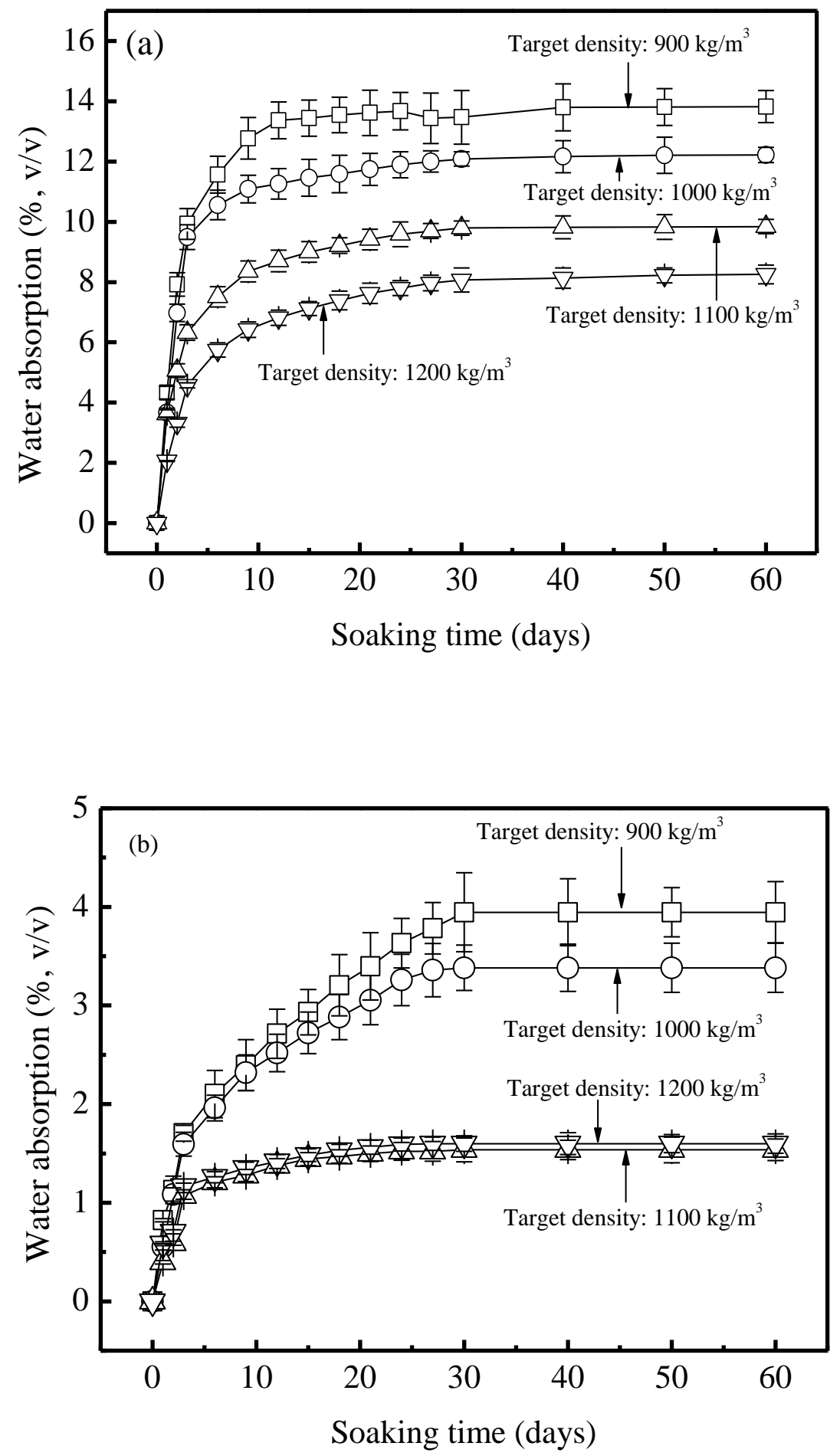

Fig. 2. Variations of water absorption with soaking time: (a) LGSS and (b) LCSS 


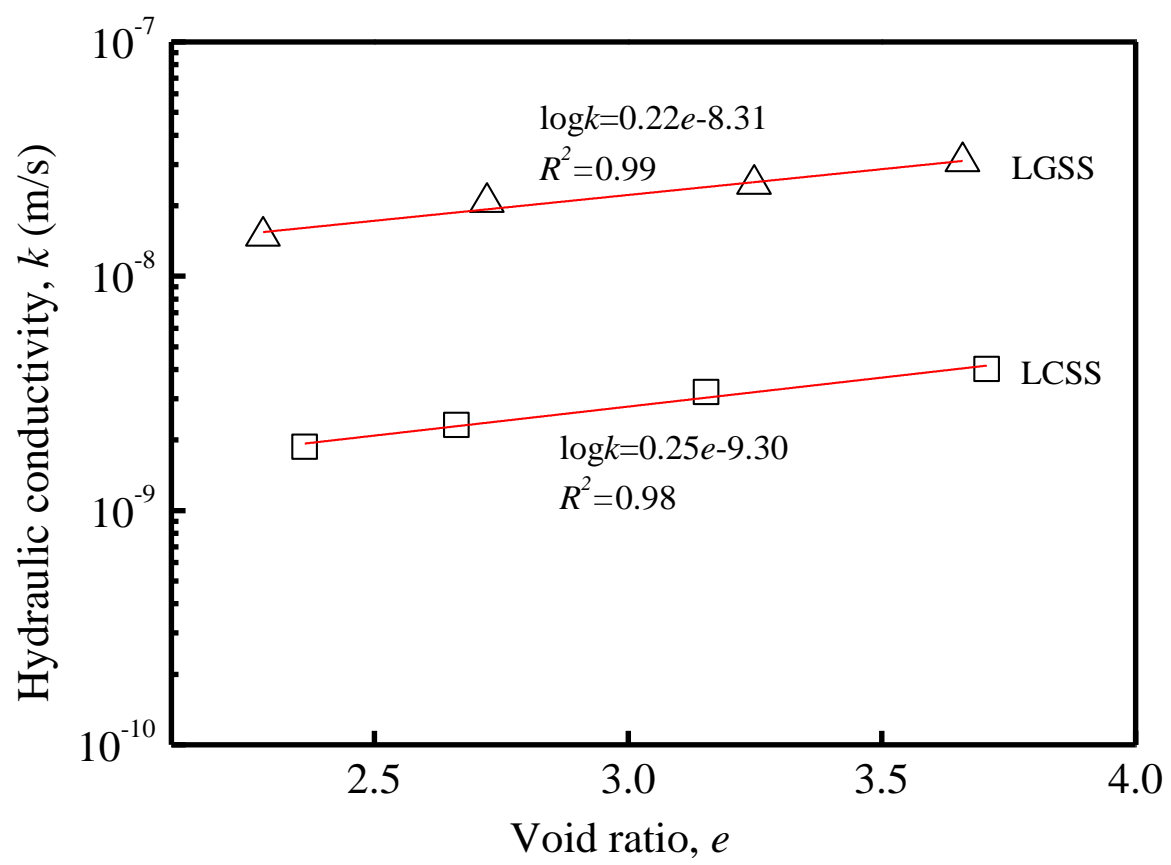

580

Fig. 3. Variations of hydraulic conductivity $(k)$ with void ratio $(e)$

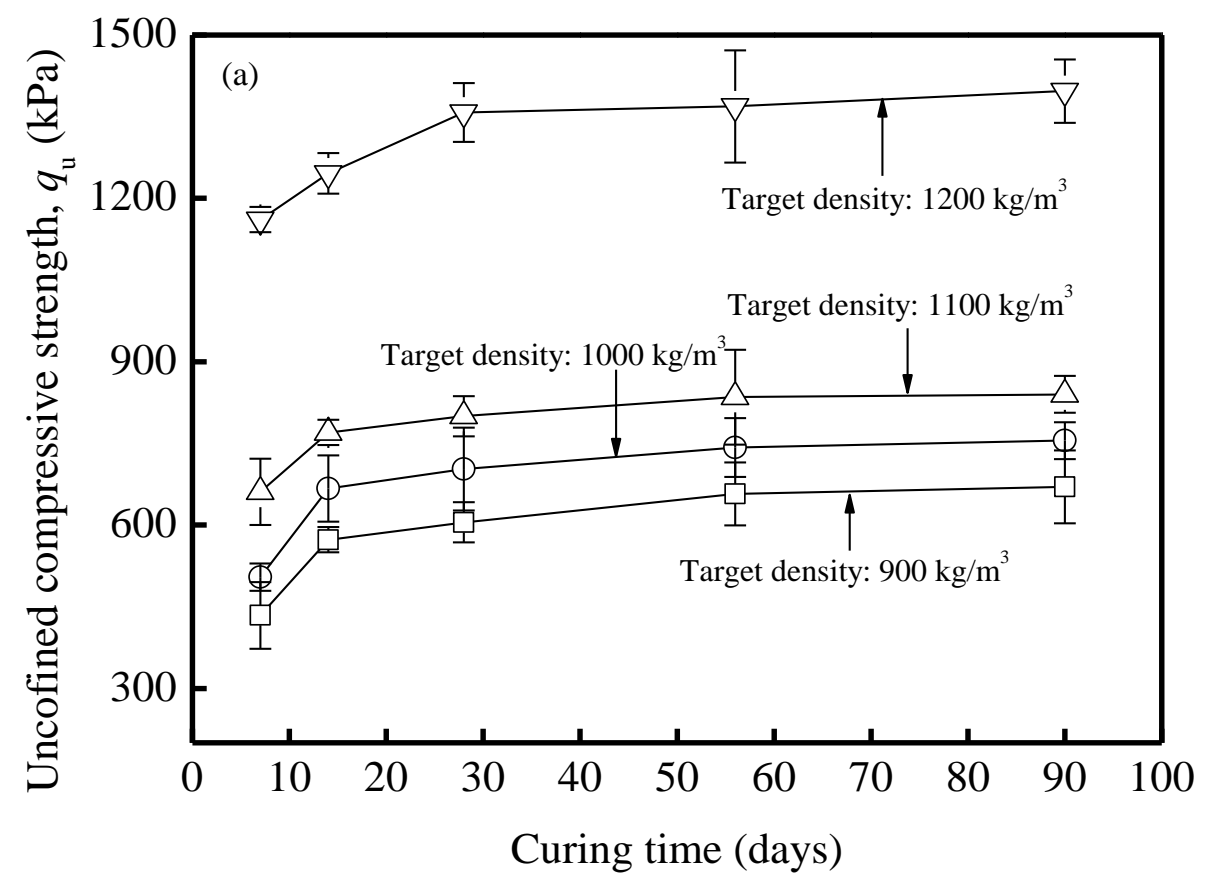



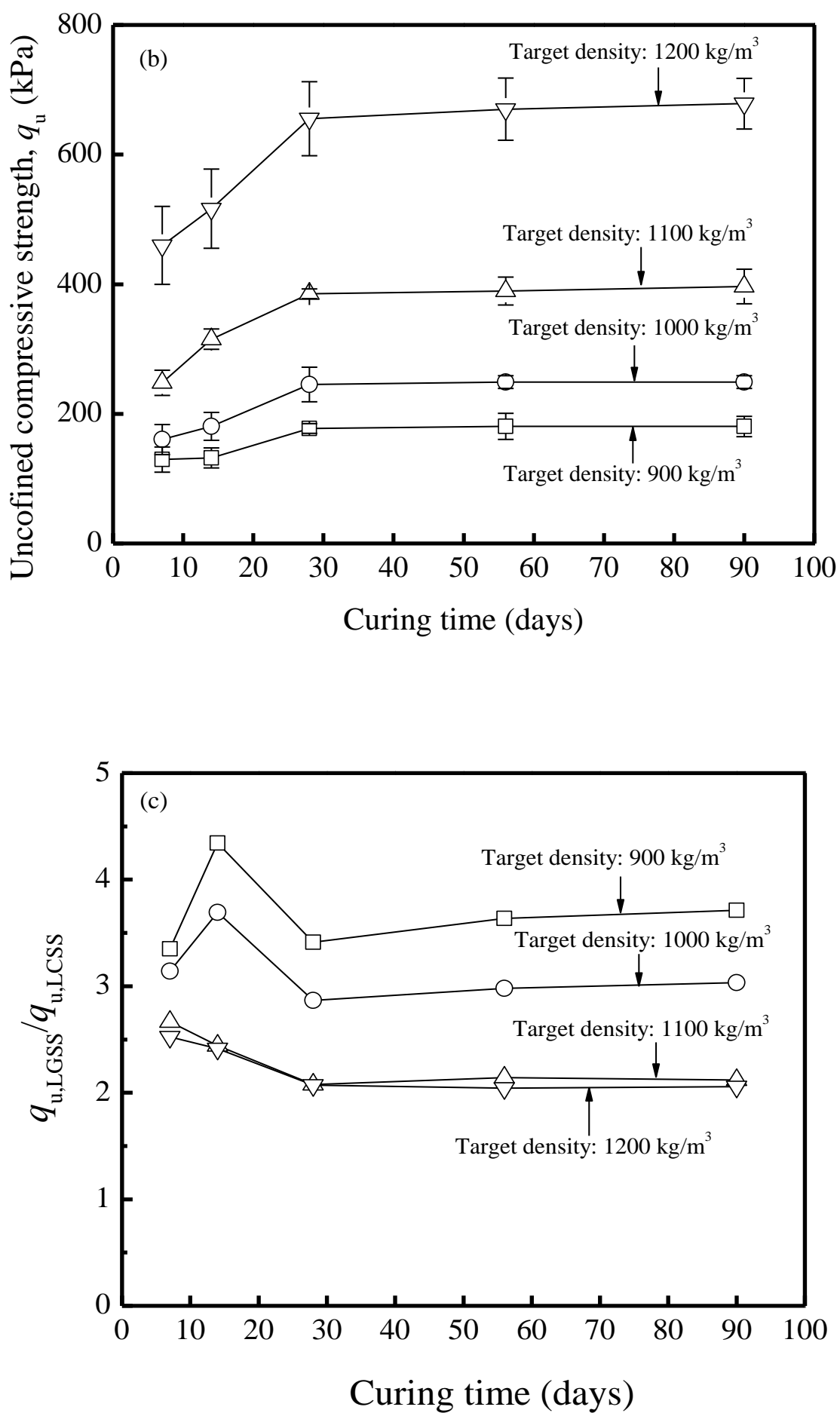

Fig. 4. Variations of $q_{\mathrm{u}}(\mathrm{SD}<5 \%$ ) for lightweight stabilized soil with the curing time: (a) 


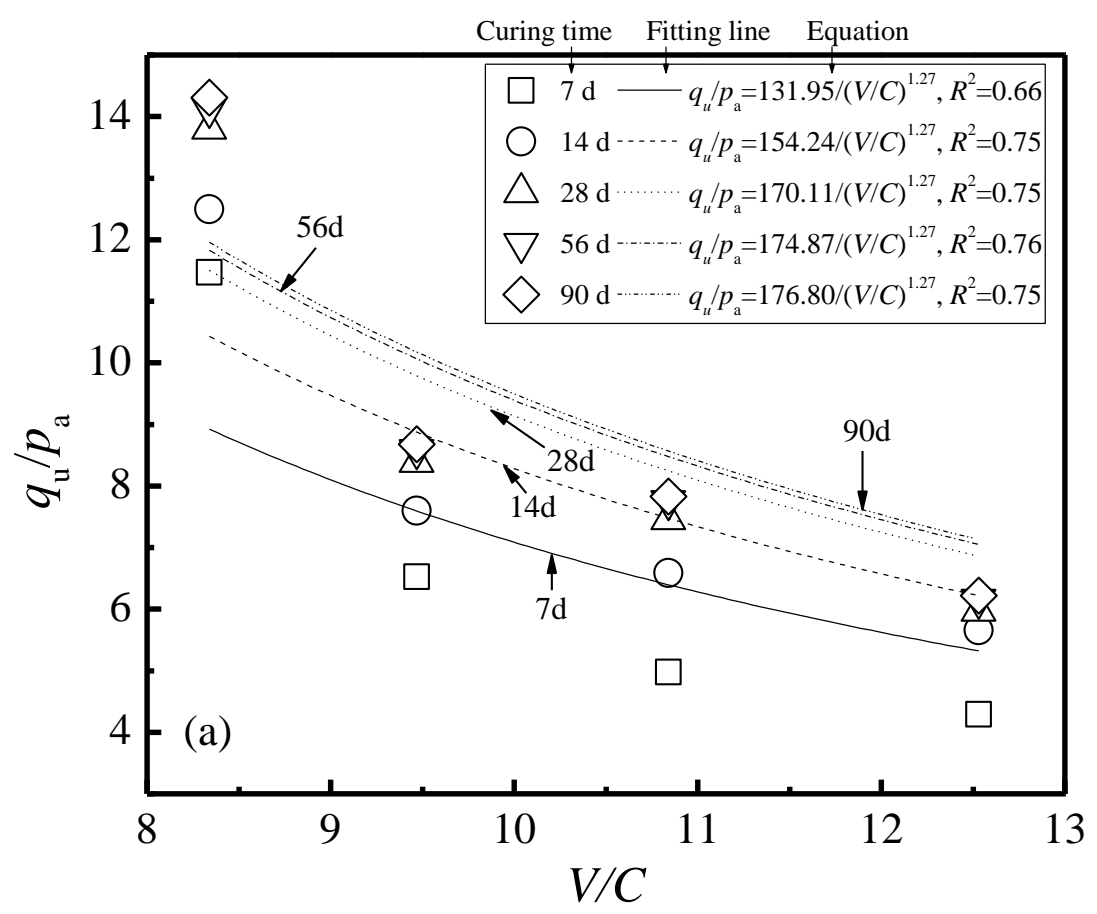

588

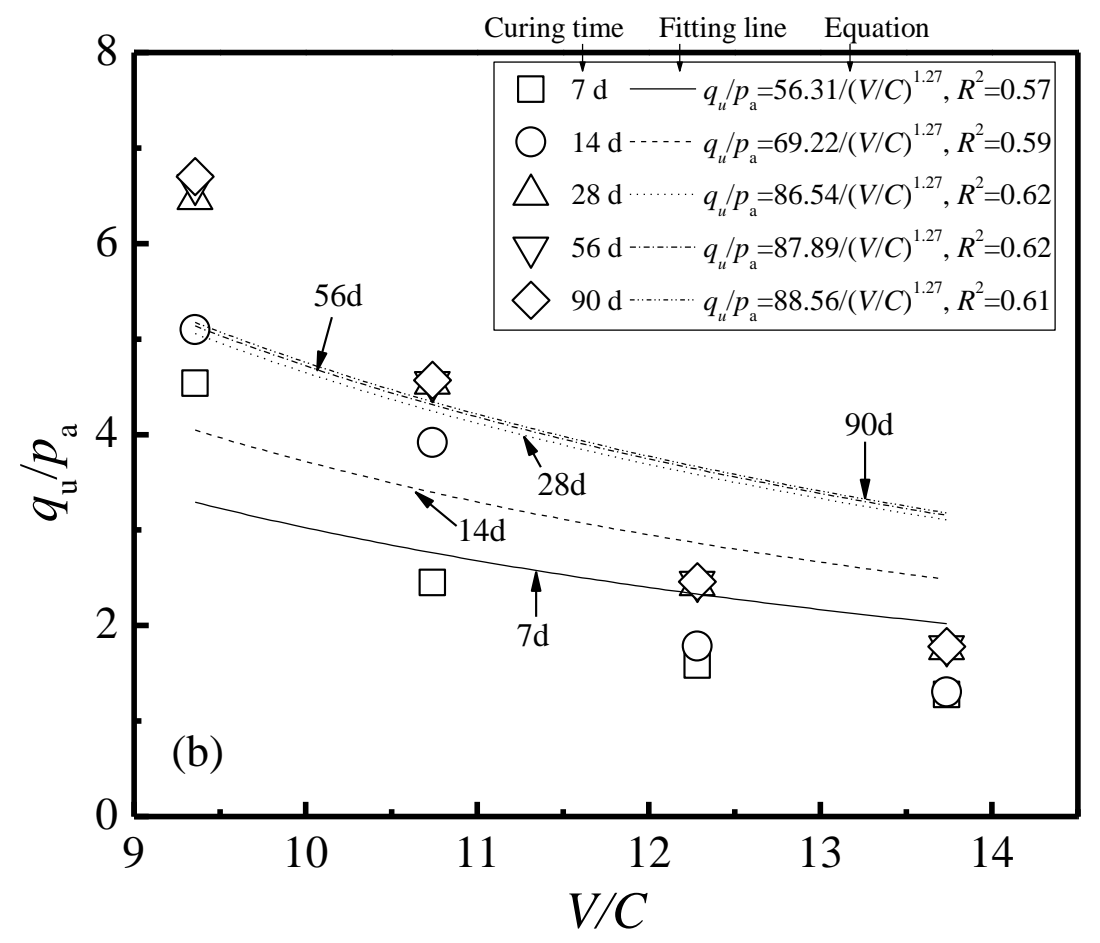




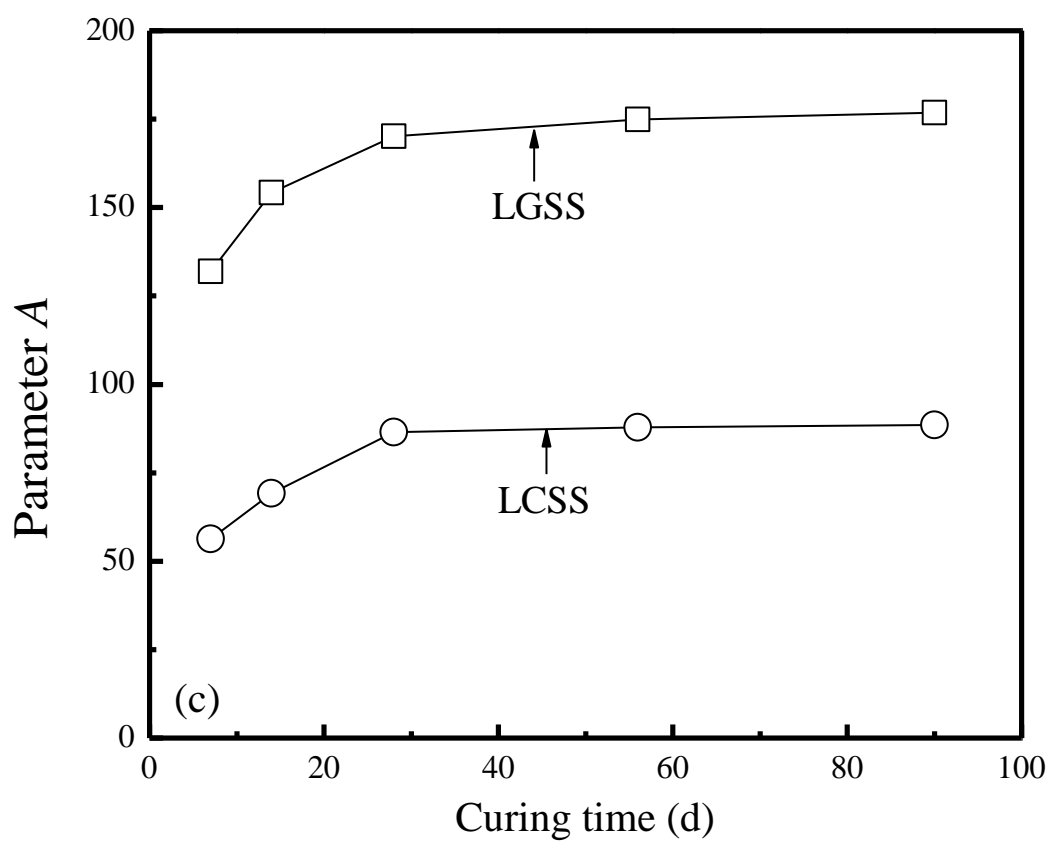

590

Fig. 5. Relationship between $q_{u} / p_{\mathrm{a}}$ and $V / C$ for lightweight stabilized soil: (a) LGSS; (b) 


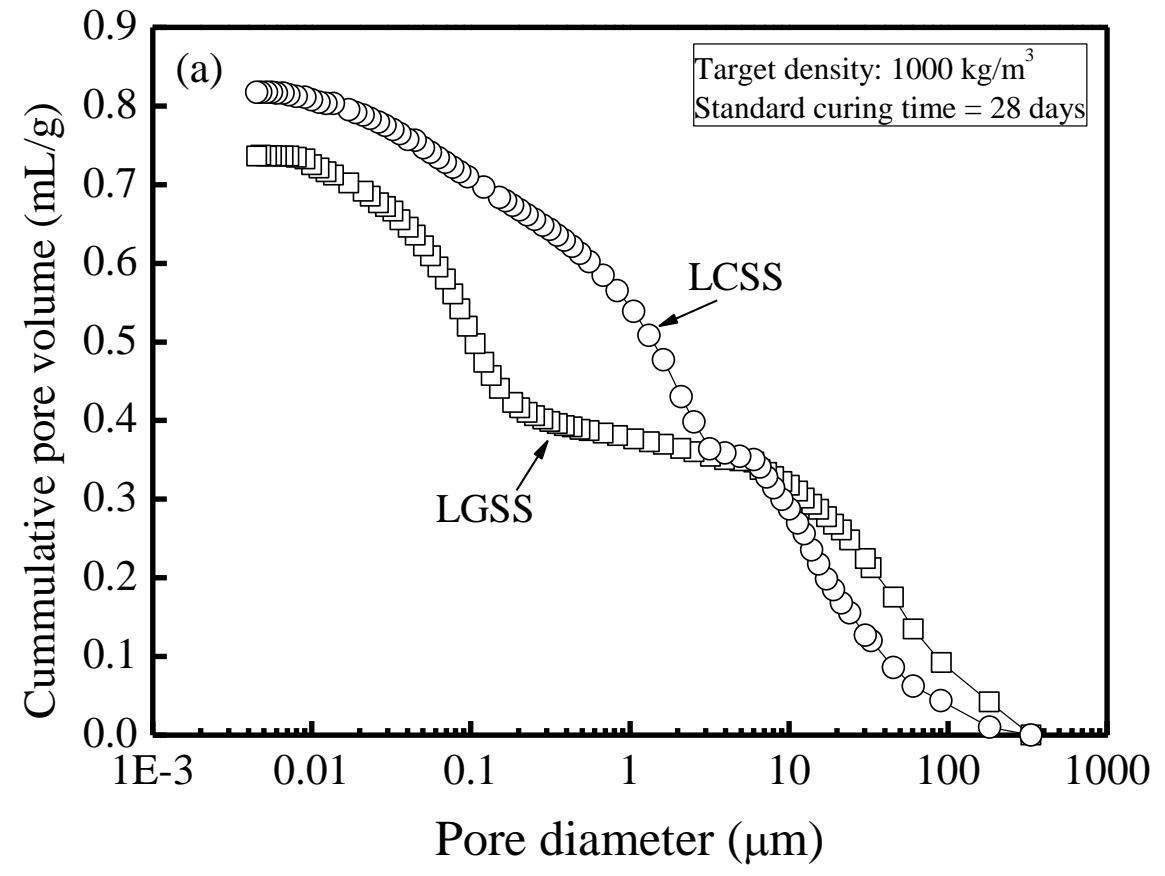

601

602

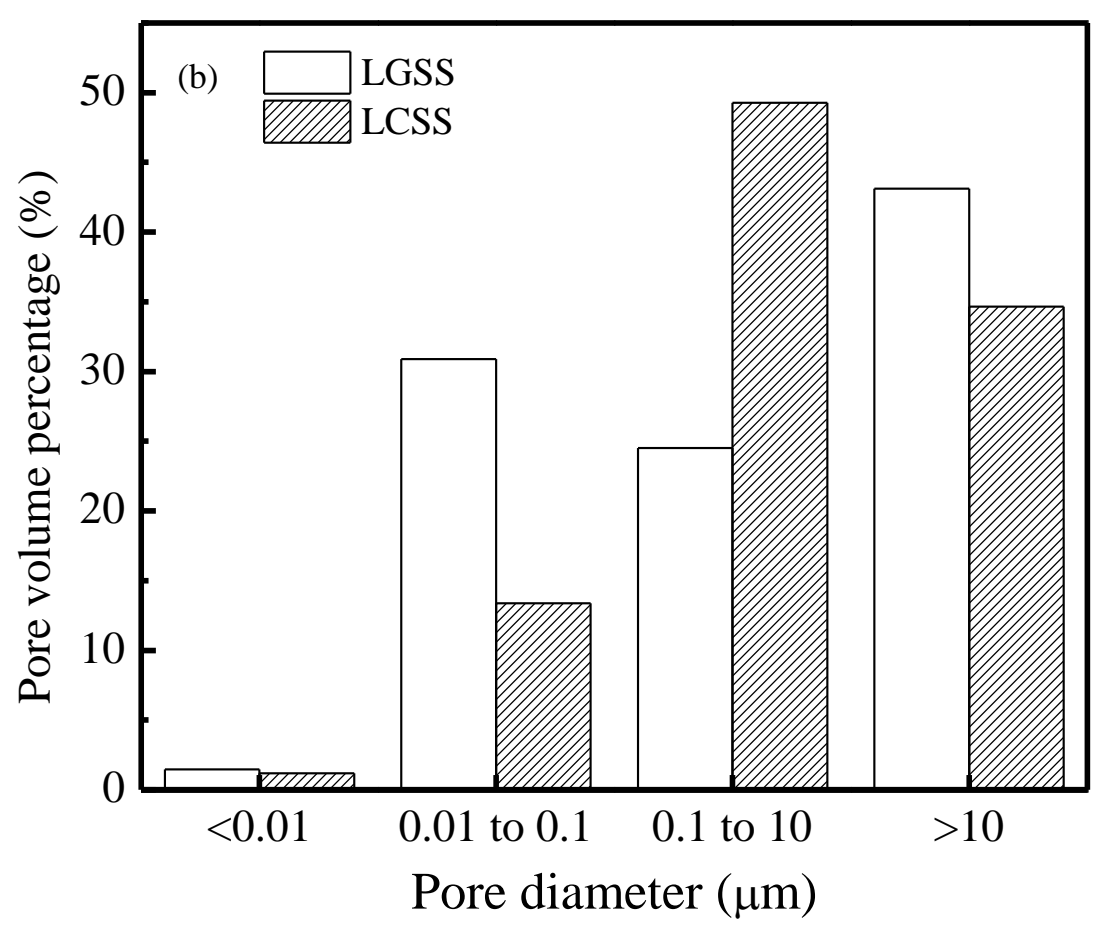

603

Fig. 7. Pore size distributions of LGSS and LCSS curing 28 days: (a) cumulative pore volume 


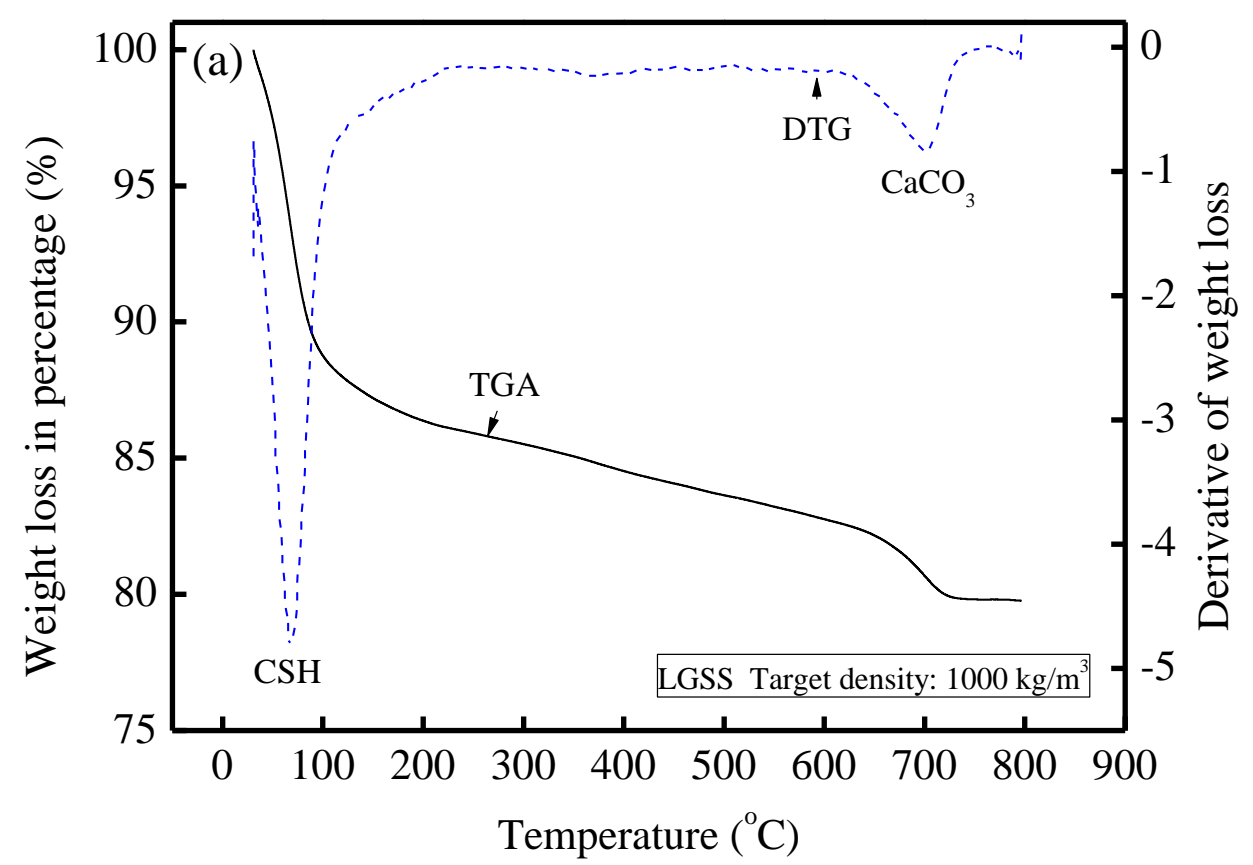

606

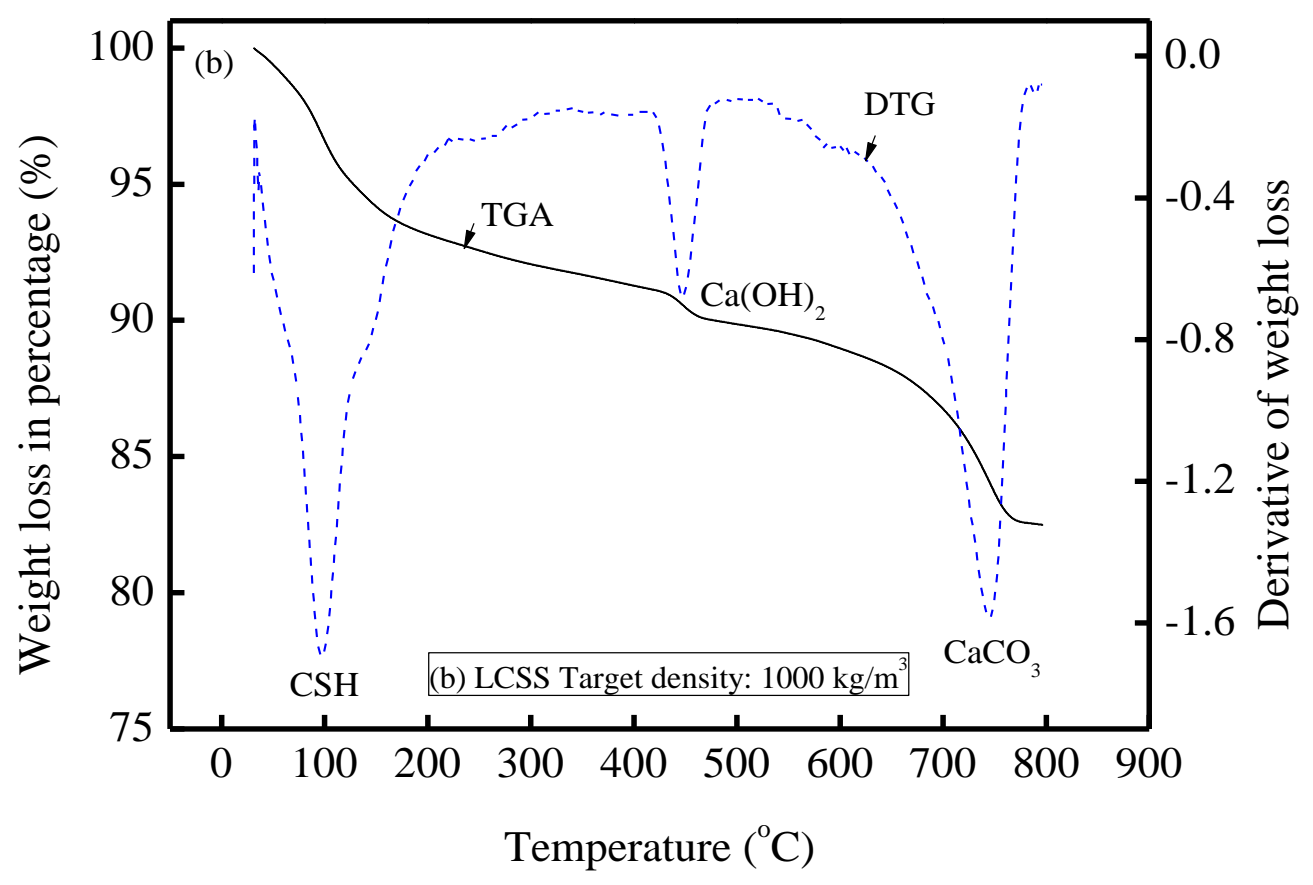

607

608

Fig. 8. TGA/DTA data of LGSS and LCSS curing for 28 days: (a) LGSS and (b) LCSS

609 